\title{
Locally Advanced Salivary Gland
} Carcinoma

National Cancer Institute

\section{Source}

National Cancer Institute. Locally Advanced Salivary Gland Carcinoma. NCI Thesaurus.

Code C158464.

A salivary gland carcinoma that has spread to nearby tissues or lymph nodes. 